\title{
MEASUREMENT OF HEPATIC BLOOD FLOW IN THE DOG BY THE BROMSULPHALEIN METHOD 1, 2
}

\author{
By ATTIE YVONNE WERNER AND STEVEN M. HORVATH
}

(From the Department of Physiology, College of Medicine, State University of Iowa, Iowa City, Ia.)

(Submitted for publication November 8, 1951 ; accepted February 5, 1952)

Estimation of hepatic blood flow by the bromsulphalein method appears to be based upon meager experimental evidence. Bradley, Ingelfinger, Bradley, and Curry (1) proposed a formula for the estimation of hepatic blood flow in man by measuring the hepatic extraction of bromsulphalein. Myers (2) compared the hepatic blood flow obtained by this method with the hepatic flow determined by urea formation. These two widely different methods yielded comparable estimates of hepatic blood flow. Sherlock, Bearn, Billing, and Paterson (3) have questioned the bromsulphalein method and have pointed out the considerable difficulties that can be experienced in the estimation of hepatic blood flow. Cohn and associates $(4,5)$ believed the high rate of extrahepatic removal of intravenously injected bromsulphalein invalidated the use of this substance for measuring hepatic blood flow. There is a need, therefore, for re-evaluation of the bromsulphalein extraction method of estimating hepatic blood flow. The reproducibility of hepatic blood flow measurements in a single animal and in a group of animals must be determined and the data so obtained subjected to analysis for statistical significance.

\section{METHODS}

Adult mongrel dogs, fasted 20 hours previous to experimentation, were anesthetized by the intravenous injection of $30 \mathrm{mg}$. nembutal $/ \mathrm{Kg}$. body weight. Under fluoroscopic guidance catheters were put through the right external jugular vein into a hepatic vein and the right ventricle. After the hepatic catheter was in position it was withdrawn slightly, still under fluoroscopic observation, to insure ease of sampling. Both the hepatic and right heart catheters were checked fluoroscopically after the bromsulphalein infusion was ended. In some instances catheters were placed in different hepatic veins.

1 This work was supported by a grant from The Life Insurance Medical Research Fund.

2 A preliminary report was given at the meeting of the Federation of American Societies for Experimental Biology, May 2, $1951^{\circ}$.
An indwelling needle or catheter was also placed in a branch of the femoral artery. All animals were heparinized, $5 \mathrm{mg} . / \mathrm{Kg}$. Blood pressures were recorded continuously by Statham strain gauges simultaneously from the femoral artery, right heart, and hepatic vein. A priming dose of bromsulphalein (BSP) was administered to raise the plasma level rapidly and to shorten the time required for equilibration. The priming dose of BSP was followed immediately by infusion of BSP at a constant rate for a period of 80 minutes.

In order to maintain a peripheral BSP concentration of less than $1 \mathrm{mg}$. per cent or greater than $1 \mathrm{mg}$. per cent, two rates or two concentrations of BSP infusions were given. The flow was controlled by the use of a Graubard Peterson flowrator. A sample of the infusion fluid was always taken for later analysis. Hepatic venous and peripheral arterial samples were withdrawn simultaneously at 10-minute intervals during the 40 to 80 minutes of each observation.

Five ml. of blood were collected in a dry syringe following preliminary flushing of the catheter by withdrawal of several ml. of blood. Hemolyzed samples were discarded. The hematocrit value was determined by the usual Wintrobe tube technique from samples of blood obtained at the midpoint of measurements of hepatic blood flow. Blood samples were also obtained from the femoral artery and right heart for the estimation of cardiac output by the Fick principle 60 minutes after the infusion had begun. The data on blood pressures and cardiac outputs are being reported in a separate communication. At the end of each period of observation incisions were sutured, 300,000 units of procaine penicillin administered and the dog returned to its cage. No animal was employed either for other observations or repeated hepatic observations until at least two or more weeks had elapsed.

BSP was measured colorimetrically in the macro unit of the Evelyn photoelectric colorimeter using filter $\mathbf{5 8 0}$. The calibration curve and the BSP solutions employed in all experiments were prepared from pure BSP powder (Hynson, Westcott, and Dunning).

One ml. of plasma was pipetted into an Evelyn colorimeter tube and the volume made up to $10 \mathrm{ml}$. with isotonic saline. After the initial "blank" reading, 2 drops of concentrated $\mathrm{NaOH}$ were added, the mixture well agitated, and a reading taken within one minute of adding the alkali. The BSP concentration was obtained from the galvanometer reading and the calibration curve. All determinations were made in duplicate. 
TABLB I

Estimated hepatic blood flow in the anesthetized dog

The infusions in 49 observations** on 17 animals ranged from 0.63-3.25 mg. BSP/min. W1th a man infusion rate of $1.73 \mathrm{mg} . \mathrm{BSP} / \mathrm{min}$. (S.E. 0.05), equivalent to $0.11 \mathrm{mg}$. BSP/Kg./min. (S.E. 0.03).

\begin{tabular}{|c|c|c|c|}
\hline & \multicolumn{3}{|c|}{ Blood Flow } \\
\hline & Range & Lean & Standard krror \\
\hline ml. $/ \mathrm{Kg} / \mathrm{min}$. & 16 to 111 & 42 & 2.9 \\
\hline ml./12/min. & 495 to 3130 & 1140 & 78 \\
\hline ml./dog/min. & 252 to 1878 & 690 & 52 \\
\hline
\end{tabular}

* Bach observation represents the mean value obtained from 3 to 6 sampline periods.

\section{CaLCULATIONS}

When the infusion rate of BSP was such as to maintain a constant blood level (P), the infusion rate was considered to be equivalent to removal (R) of BSP and then the Fick principle could be applied. Estimated hepatic blood flow (E.H.B.F.) was calculated by the method of Bradley and associates (1) by the following formula :

$$
\text { E.H.B.F. }=\frac{\mathrm{R}}{0.01(\mathrm{P}-\mathrm{H})} \times \frac{1}{1-\text { hematocrit' }}
$$

where $P$ represents the concentration of $B S P$ in $\mathrm{mg} . / 100$ $\mathrm{ml}$. in the afferent hepatic blood and $\mathrm{H}$ the concentration in the efferent hepatic blood. Hepatic blood flow was calculated only from those 10-minute sampling periods where the level of BSP in the peripheral blood was constant or changing less than $0.0005 \mathrm{mg} . / \mathrm{ml} . / \mathrm{min}$. The BSP values utilized for the calculation of changing levels were interpolated midpoints on concentration curves of measured values. From three to five calculations were made from successive 10 -minute sampling periods during each observation. The average of these 10 -minute sampling periods was used to represent the E.H.B.F. of each observation. These averages were utilized in the calculations of the mean estimated hepatic blood flow.

\section{RESULTS}

The mean estimated hepatic flow was determined to be $690 \mathrm{ml} . / \mathrm{dog} / \mathrm{min}$. in 49 observations on 17 animals. This was equivalent to $42 \mathrm{ml}$./ $\mathrm{Kg} . / \mathrm{min}$. or $1,140 \mathrm{ml} . / \mathrm{M}^{2} / \mathrm{min}$. (Table I). ${ }^{\mathrm{s}}$ Equilibrium of BSP in the peripheral blood usually had occurred by the time the first sample was taken 40 minutes after infusion had begun.

The mean extraction of BSP by the liver for all observations was 34 per cent with a range of from 9 to 63 per cent. The percentage extraction

${ }^{3} \mathrm{~A}$ table of detailed data for this paper has been deposited with the American Documentation Institute, 1719 N Street, N. W., Washington 6, D. C. of BSP was not significantly greater at lower than at higher peripheral BSP levels (Figure 1).

The livers of the dogs used in these observations were not weighed immediately after the observation period but autopsy records in this laboratory showed a liver weight averaging 3 per cent of the dog's body weight. The blood flow calculated on the basis of a liver weight of 3 per cent of body weight ranged from 57 to $358 \mathrm{ml} . / 100$ gr. liver/ min. with a mean value of $140 \mathrm{ml} . / 100 \mathrm{gr}$. liver/ min., S.E. 8.2.

The reproducibility of E.H.B.F. in any one dog was determined. In comparison with the larger series of 49 observations on 17 dogs, the general reproducibility for any one dog was poor. However, in a few instances remarkably good agreement was obtained (Table II).

Catheters were placed in hepatic veins in the left lateral and right lateral lobes of the liver in order to estimate hepatic flow. Blood samples obtained from these two sampling sites were found to have approximately the same BSP concentration, and the calculated hepatic blood flows were similar.

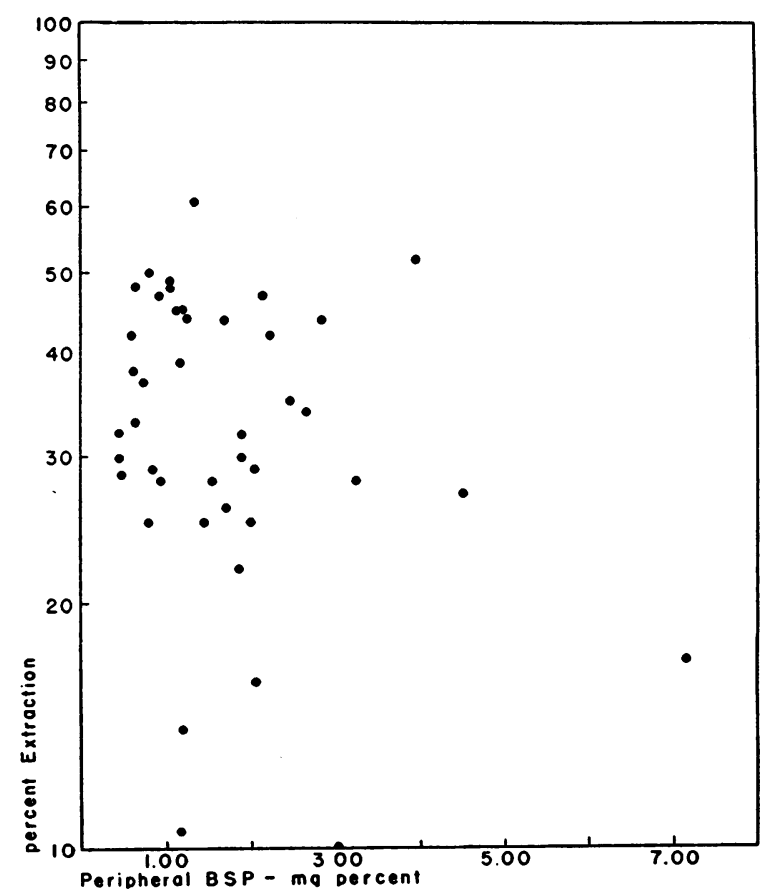

Fig. 1. The Rriationship of Peripheral Bromsulphalein Values to the Per Cent Extraction by the LIVER

The trend line as obtained by the method of least squares is $\mathbf{y}=-2 x+37.5$. 
TABLE II

Reproducibility of estimated blood flow measurement in the dog

\begin{tabular}{ccccc} 
Dop no. & $\begin{array}{c}\text { Woight } \\
\text { Kg. }\end{array}$ & $\begin{array}{c}\text { No. of } \\
\text { observations }\end{array}$ & $\begin{array}{c}\text { Mean E.H.B.F. } \\
\text { ml./Kg./min. }\end{array}$ & S.E. \\
\hline 46 & 12.4 & 7 & 43 & 4.2 \\
47 & 13.3 & 6 & 26 & 2.2 \\
48 & 19.2 & 4 & 33 & 4.4 \\
44 & 15.2 & 4 & 50 & 6.5 \\
32 & 16.9 & 3 & 43 & 8.3 \\
55 & 20.3 & 3 & 49 & 6.9 \\
56 & 19.0 & 3 & 37 & 0.7 \\
36 & 18.0 & 2 & 33.5 & 3.5 \\
43 & 114.6 & 2 & 23.5 & 6.5 \\
52 & 18.8 & 2 & 28.5 & 2.5 \\
53 & 14.9 & 2 & &
\end{tabular}

These latter values fell within the statistical range reported above. The exact hepatic vein utilized to obtain hepatic blood samples does not appear to be of much consequence in explaining the variability of E.H.B.F.

Extreme variability was observed between any two compared 10-minute sampling periods. Although it was hoped the dogs would be maintained in a relatively constant state by the anesthesia, a mean range of change of 11 to 17.5 per cent was found (Table III). The lowest to the highest values during the three or more sampling periods were analyzed in order to determine the maximum in the variability. A mean difference of 29 per cent was found. The lowest E.H.B.F. did not necessarily occur in the 40/50-minute sampling period nor the highest in the 70/80-minute sampling period, nor vice versa, but could occur in any sampling period. The variations in the 10-minute blood samples were primarily due to variations in hepatic venous BSP concentration and to a lesser extent to changes in arterial BSP concentration.

An infusion of either a low concentration of $\mathrm{BSP}$ or of a high concentration of BSP was given

TABLE III

Comparison of estimated blood flows during various 10minute sampling periods

\begin{tabular}{|c|c|c|}
\hline Sampling perlods compared & $\frac{\text { Woan difference }}{\text { por cent }}$ & $\frac{\text { Indinew range of difference }}{\text { per cent }}$ \\
\hline 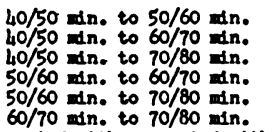 & $\begin{array}{l}13 \\
15.5 \\
17.5 \\
11 \\
17 \\
11\end{array}$ & $\begin{array}{l}-35 \text { to }+62 \\
-28 \text { to }+57 \\
-48 \text { to }+57 \\
-40 \text { to }+47 \\
-54 \text { to }+38 \\
-45 \text { to }+36\end{array}$ \\
\hline $\begin{array}{l}\text { period with to period with } \\
\text { lowest BHBF }\end{array}$ & 29 & 0 to +119 \\
\hline
\end{tabular}

TABLE IV

Comparison of estimated hepatic blood flow when there was marked difference in the peripheral bromsulphalein concentration

Peripheral BSP Concentrations greater than 1 ess than $1 \mathrm{mg}$. per cent $1 \mathrm{gg}$. per cent

No. of observations

$\begin{array}{rr}27 & 18 \\ 1040 & 1311 \\ 85 & 100\end{array}$

$t$ value 2.1

in an attempt to produce a peripheral concentration of greater than $1 \mathrm{mg}$. per cent with high infusion rates or concentrations and less than $1 \mathrm{mg}$. per cent with low infusions. A comparison was made when the hepatic blood flows were divided into two groups based on these two levels of peripheral BSP concentration. The difference in blood flow was significant within the 5 per cent level (Table IV, Figure 2). It was possible to evaluate nine paired samples of data from dogs that were given both high and low infusions of

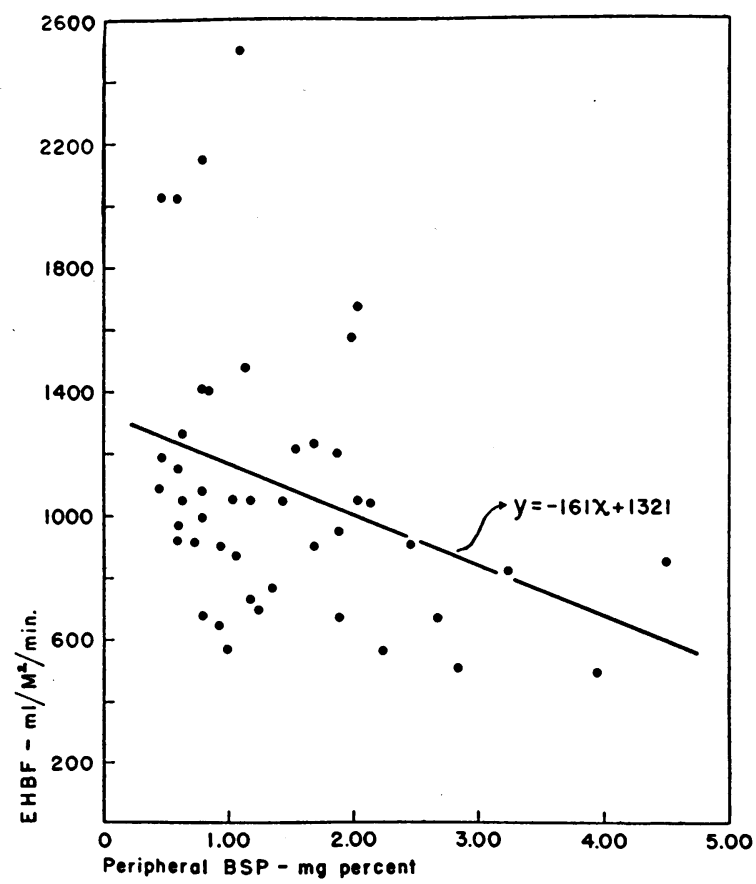

Fig. 2. The Relationship of Peripheral Bromsutphalein Values to the Estimated Hepatic Blood Frow

The trend line was obtained by the method of least squares, $\mathrm{y}=-161 x+1,321$. 


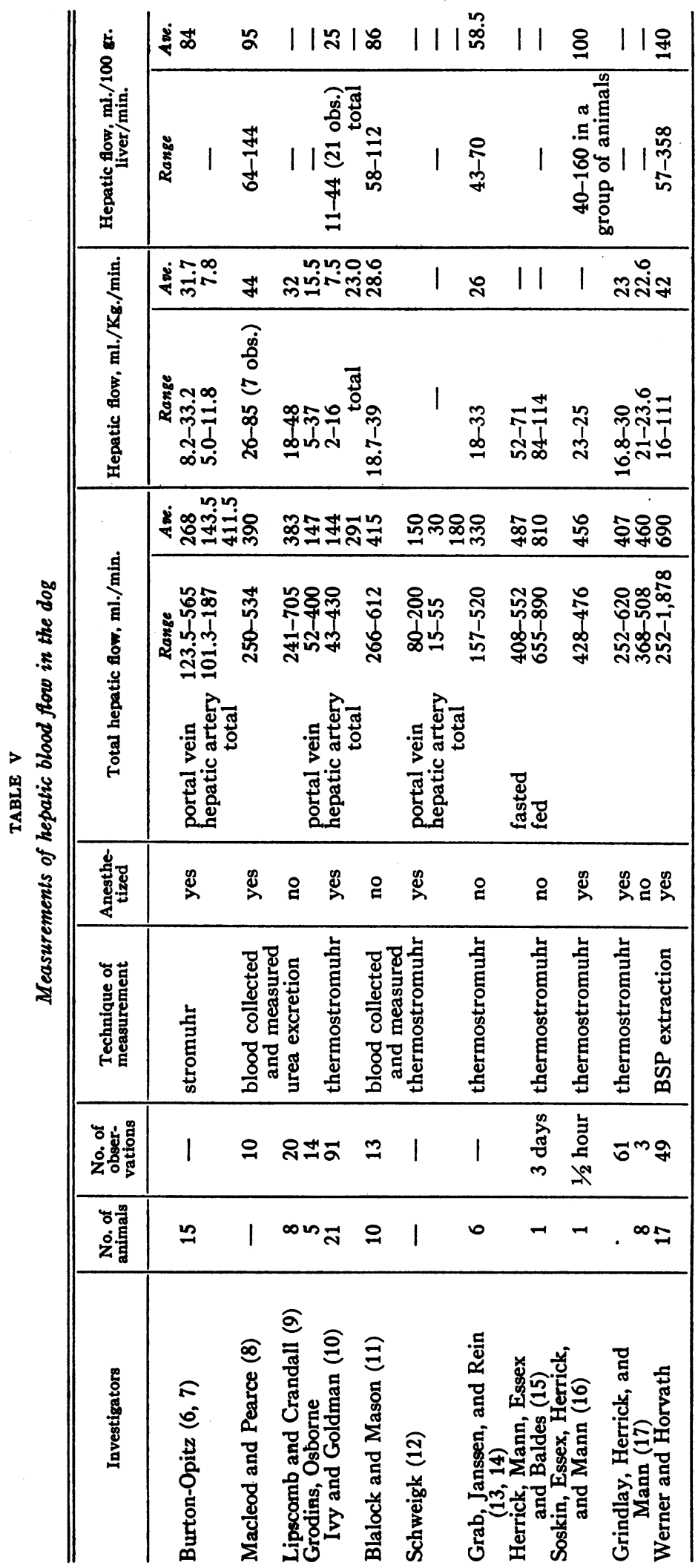


BSP on the same day. The E.H.B.F. was calculated to be $1,146 \mathrm{ml} . / \mathrm{M}^{2} / \mathrm{min}$. with a peripheral BSP concentration of greater than $1 \mathrm{mg}$. per cent. When the peripheral BSP concentration was less than $1 \mathrm{mg}$. per cent, the E.H.B.F. was calculated to be $1,211 \mathrm{ml} . / \mathrm{M}^{2} / \mathrm{min}$. The mean difference in flow between the two peripheral levels was $65 \mathrm{ml}$. with a standard error of 1.08 and a $t$ value of 0.60 . Therefore, the slightly significant difference found on analysis of all samples was not confirmed when paired data were analyzed.

The data were subjected to further statistical analysis according to whether the infusion was greater or less than $0.10 \mathrm{mg} . / \mathrm{Kg} . / \mathrm{min}$. In 15 paired samples, the E.H.B.F. was $1,016 \mathrm{ml} . / \mathrm{M}^{2} /$ min. with an infusion of greater than $0.10 \mathrm{mg}$./ $\mathrm{Kg}$./min. When the infusion was less than 0.10 $\mathrm{mg} . / \mathrm{Kg} . / \mathrm{min}$., the E.H.B.F. was $1,079 \mathrm{ml} . / \mathrm{M}^{2} /$ min. The mean difference in flow between the two infusion levels was $63 \mathrm{ml}$. with a standard error of 0.81 and a $t$ value of 0.8 .

\section{DISCUSSION}

Hepatic blood flow determined in anesthetized dogs by methods other than the bromsulphalein extraction method has averaged around $375 \mathrm{ml}$./ min. (Table V). Grindlay, Herrick, and Mann (17) reported hepatic blood flow in the dog to average $23 \mathrm{ml} . / \mathrm{Kg} . / \mathrm{min}$. without anesthesia and $22.6 \mathrm{ml} . / \mathrm{Kg} . / \mathrm{min}$. with anesthesia. Habif and associates (18) measured hepatic blood flow in two patients before and during thiopental anesthesia and found a decreased hepatic flow in one and an increased hepatic flow in the other, while three other patients under cyclopropane anesthesia showed a reduced hepatic flow. The range of hepatic flow in anesthetized dogs was rather large as determined by one technique such as the thermostromuhr or by several methods such as direct collection of blood, stromuhr, and thermostromuhr. The mean flows ranged from 23 to $39.5 \mathrm{ml}$. $/ \mathrm{Kg}$./ min. and from 84 to $95 \mathrm{ml} . / 100 \mathrm{gr}$. liver $/ \mathrm{min}$. Because of the wide range observed with these several methods it is probable that this range represents spontaneous variations in blood flow rather than variations in measurement due to the method employed. The values being reported for anesthetized dogs by the bromsulphalein extraction method are in excess of those obtained with other techniques (Table V). Lorber and co-workers $(19,20)$ have pointed out that BSP is found in the portal and hepatic veins and femoral artery after duodenal instillation of BSP suggesting that the amount of BSP normally excreted into the intestine via the bile must be considered in any evaluation of techniques using BSP. However, Owen (21) found no BSP in the peripheral blood after gastric or duodenal instillation of BSP. Cohn and associates $(4,5)$ have found that only 50 per cent of BSP infused into an evisceratehepatectomized-nephrectomized preparation remained 60 minutes later.

Preliminary experiments in this laboratory indicated that the extrahepatic removal of BSP was approximately 20 per cent, which is in agreement with the data of Brauer and Pessotti (22). Correcting the data obtained by the BSP method for this 20 per cent loss of the dye from the peripheral blood, the hepatic blood flow would be $24.5 \mathrm{ml}$./ $\mathrm{Kg}$. $/ \mathrm{min}$. This is equivalent to $403 \mathrm{ml} . / \mathrm{dog} / \mathrm{min}$., $665 \mathrm{ml} . / \mathrm{M}^{2} / \mathrm{min}$. and $82 \mathrm{ml} . / 100 \mathrm{gr}$. liver $/ \mathrm{min}$. These corrected values are in close agreement with those obtained by other methods.

There was no difference in hepatic blood flow when the peripheral BSP concentration was greater or less than $1 \mathrm{mg}$. per cent. These results are in marked contrast to those presented for man by Sherlock and co-workers (3). These investigators pointed out that when the peripheral concentration of BSP was less than $1 \mathrm{mg}$. per cent, calculated hepatic blood flow appeared to be too great. This blood flow was almost twice that calculated when the peripheral BSP concentration was above $1 \mathrm{mg}$. per cent. The suggestion was made that at low levels of BSP concentration extrahepatic withdrawal might be a serious source of error. Ingelfinger (23) stated that the greatest error in calculating hepatic blood flow by the bromsulphalein method might occur at high peripheral BSP levels. The hepatic flow values reported here for the dog indicated that differences in flow were not due to different peripheral BSP levels. There was poor correlation between the peripheral BSP level and the E.H.B.F. in the dog, as Sherlock and associates (3) have shown to be true also for man. The percentage extraction of BSP was not significantly greater at lower peripheral BSP levels in the dog, unlike the correlation found in man (3). 
The variations in hepatic blood flow determined by the BSP method are great. Because of these variations several 10-minute sampling periods must be used to evaluate blood flow. A single 10minute sampling period is inadequate. The variation in flow which occurs may be explained either by a lack of sensitivity inherent in the method or by spontaneous variations in the normal state of the animals. Regardless of difficulties due to methodology, such as corrections needed for extrahepatic dye loss, the method appears valid within determined statistical ranges. Therefore, it is suggested that normal hepatic blood flow in dogs is subject to wide spontaneous variations. Corrected blood flow measurement is in agreement with hepatic flow studies determined by the thermostromuhr and other methods $(7,11,16,17)$.

The extreme variation in the hepatic flow even in the anesthetized dog may be due in part to the sphincter mechanism described in the dog (24), which may or may not be present in man. Several studies have indicated an intermittent and irregular rhythmicity of hepatic blood flow which Grindlay, Herrick, and Mann (17) showed may be due to alternate storage and discharge of blood by the liver.

Caution must be employed in any evaluation of hepatic blood flow measured by the BSP method. Since normal hepatic flow in the dog is subject to wide spontaneous variation, it is valid to evaluate changes in flow produced by drugs or by stimulation only when the changes observed are statistically different from control blood flow.

\section{CONCLUSIONS}

1. The estimated hepatic blood flow (E.H. B.F.) has been determined in 49 observations on 17 anesthetized dogs by the bromsulphalein (BSP) extraction method using hepatic vein catheterization. The mean E.H.B.F. was found to be $42 \mathrm{ml}$./ $\mathrm{Kg}$./min., S.E. 2.9. This is equivalent to $690 \mathrm{ml}$./ $\mathrm{dog} / \mathrm{min}$., $1,140 \mathrm{ml} . / \mathrm{M}^{2} / \mathrm{min}$. or $140 \mathrm{ml} . / 100 \mathrm{gr}$. liver $/ \mathrm{min}$. These figures are too high apparently due to extrahepatic loss of BSP.

2. Deviations in hepatic flow determined from different sampling sites in the liver do not appear to exceed changes in hepatic flow from animal to animal or in the same animal on different occasions.
3. Differences in peripheral BSP concentration or differences in rates and concentrations of BSP infusion cause no significant difference in hepatic blood flow determinations.

4. Hepatic blood flow is subject to wide spontaneous variation. A single observation represents only the blood flow under conditions during that period of observation.

\section{ACKNOWLEDGMENTS}

The authors are greatly indebted to Mrs. Doris W. Knapp, Mr. D. M. MacCanon, and Mr. B. K. Hutt for their aid during portions of this investigation.

\section{REFERENCES}

1. Bradley, S. E., Ingelfinger, F. J., Bradley, G. P., and Curry, J. J., The estimation of hepatic blood flow in man. J. Clin. Invest., 1945, 24, 890.

2. Myers, J. D., The hepatic blood flow and splanchnic oxygen consumption of man-their estimation from urea production or bromsulphalein excretion during catheterization of the hepatic veins. J. Clin. Invest., 1947, 26, 1130.

3. Sherlock, S., Bearn, A. G., Billing, B. H., and Paterson, J. C. S., Splanchnic blood flow in man by the bromsulfalein method: the relation of peripheral plasma bromsulfalein level to the calculated flow. J. Lab. \& Clin. Med., 1950, 35, 923.

4. Cohn, C., Levine, R., and Streicher, D., The rate of removal of intravenously injected bromsulphalein by the liver and extrahepatic tissues of the dog. Am. J. Physiol., 1947, 150, 299.

5. Cohn, C., Levine, R., and Kolinsky, M., Hepatic and peripheral removal rates, in the dog, for intravenously injected bromsulphalein. Am. J. Physiol., 1948, 155, 286.

6. Burton-Opitz, R., The vascularity of the liver. I. The flow of the blood in the hepatic artery. Quart. J. Exper. Physiol., 1910, 3, 297.

7. Burton-Opitz, R., The vascularity of the liver. IV. The magnitude of the portal inflow. Quart. J. Exper. Physiol., 1911, 4, 113.

8. Macleod, J. J. R., and Pearce, R. G., The outflow of blood from the liver as affected by variations in the condition of the portal vein and hepatic artery. Am. J. Physiol., 1914, 35, 87.

9. Lipscomb, A., and Crandall, L. A., Jr., Hepatic blood flow and glucose output in normal unanesthetized dogs. Am. J. Physiol., 1947, 148, 302.

10. Grodins, F. S., Osborne, S. L., Ivy, A. C., and Goldman, L., The effect of bile acids on hepatic blood flow. Am. J. Physiol., 1941, 132, 375.

11. Blalock, A., and Mason, M. F., Observations on the blood flow and gaseous metabolism of the liver of the unanesthetized dog. Am. J. Physiol., 1936, 117, 328. 
12. Schweigk, $H$., Untersuchungen über die Leberdurchblutung und den Pfortaderkreislauf. Arch. f. exper. Path. u. Pharmakol., 1932, 168, 693.

13. Grab, W., Janssen, S., and Rein, H., Die leber als Blutdepot. Klin. Wchnschr., 1929, 8, 1539.

14. Grab, W., Janssen, S., and Rein, H., Uber die Grösse der Leberdurchblutung. Ztschr. f. Biol., 1929, 89, 324.

15. Herrick, J. F., Mann, F. C., Essex, H. E., and Baldes, E. J., The effect of the digestion of food on the blood flow from the liver of the dog. Am. J. Physiol., 1934, 109, 52.

16. Soskin, S., Essex, H. E., Herrick, J. F., and Mann, F. C., The mechanism of the regulation of the blood sugar by the liver. Am. J. Physiol., 1938, 124, 558.

17. Grindlay, J. H., Herrick, J. F., and Mann, F. C., Measurement of the blood flow of the liver. Am. J. Physiol., 1941, 132, 489.

18. Habif, D. V., Papper, E. M., Fitzpatrick; H. F., Lowrence, P., Smythe, C. McC., and Bradley, S. E., The renal and hepatic blood flow, glomerular filtration rate, and urinary output of electrolytes during cyclopropane, ether, and thiopental anes- thesia, operation, and the immediate postoperative period. Surgery, 1951, 30, 241.

19. Lorber, S. H., Shay, H., and Siplet, H., The enterohepatic circulation of bromsulphalein: observations on hepatic, portal and arterial dye concentrations after intra-duodenal and intra-portal bromsulphalein administration. Federation Proc., 1951, 10, 86.

20. Lorber, S. H., and Shay, H., The enterohepatic circulation of bromsulphalein. Am. J. M. Sc., 1951, 221, 114.

21. Owen, C. A., Jr., The effect of the enterohepatic circulation on the bromsulfalein test of hepatic function. J. Lab. \& Clin. Med., 1951, 38, 583.

22. Brauer, R. W., and Pessotti, R. L., Hepatic uptake and biliary excretion of bromsulphthalein in the dog. Am. J. Physiol., 1950, 162, 565.

23. Ingelfinger, F. J., Hepatic function with respect to bromsulphalein removal. Bull. New England M. Center, 1947, 9, 25.

24. Thomas, W. D., and Essex, H. E., Observations on the hepatic venous circulation with special reference to the sphincteric mechanism. Am. J. Physiol., 1949, 158, 303. 